\title{
A CRISE DO PARADIGMA NEOLIBERAL E O ENIGMA DE 2002
}

\author{
Juarez Guimarães \\ Professor no Departamento de Ciência Política da UFMG. Autor de Democracia e marxismo: crítica à razão liberal
}

\begin{abstract}
Resumo: O ensaio procura pensar a conjuntura brasileira - a partir da crise da coalizão política que se formou em 1994 - tendo em vista as próximas eleições presidenciais. O argumento central focaliza a crise do projeto de refundação neoliberal do Estado brasileiro que predominou durante os anos 90. A dinâmica da conjuntura atual é pensada como expressão dessa crise em seus complexos desdobramentos.

Palavras-chave: conjuntura; neoliberalismo; crise.
\end{abstract}

$\mathrm{O}$ elemento decisivo que organiza a conjuntura brasileira atual é a crise do paradigma neoliberal de refundação do Estado brasileiro. É verdade que se trata de um fenômeno internacional, cujas origens remontam às derrotas históricas de Reagan e Thatcher, que passa pela sucessão de crises financeiras internacionais e alcança a dimensão de verdadeiras tragédias coletivas nos países, antes chamados de "emergentes", que aplicaram o receituário neoliberal.

Essas últimas crises dramáticas foram muito visíveis na América Latina nos anos 90. O Brasil, porém, viveu o impacto neoliberal de modo retardatário, incerto com o governo Collor e de forma avassaladora com os governos FHC.

O tempo próprio do neoliberalismo no Brasil fez com que o país vivesse, quase desde o início da implantação do programa, as turbulências causadas pela exposição à especulação financeira internacional, com repercussões drásticas sobre as possibilidades de um período de crescimento acelerado, mesmo que em forma de surto não sustentado em uma dinâmica de bases sólidas.

O caráter retardatário da aplicação do programa neoliberal no Brasil tem raiz política: a crise do regime militar e a ofensiva democrática e popular nos anos 80 fecharam o espaço para o domínio neoliberal. Assim, apenas em 1994 é que se criaram as condições políticas para um programa de refundação liberal do Estado brasileiro.
O centro do programa neoliberal no Brasil foi muito mais do que uma reforma do Estado brasileiro, em suas dimensões de gestão administrativa e racionalização. Ao incidir sobre o vazio político de um país recém-constitucionalizado - em um contexto em que faltava implantar as diretrizes da Constituição de 1988 e regulamentar parte importante de seu texto - e tornar exponencial o uso das medidas provisórias, promovendo seguidas reformas constitucionais, o governo FHC impulsionou verdadeira refundação neoliberal do Estado brasileiro (Couto, 1998). Isso significou a revisão decisiva de vários de seus contratos básicos e fundamentais em uma direção liberal, com intensidade inédita na história republicana do século XX.

Em primeiro lugar, alterou-se o padrão das relações entre o Estado brasileiro e o mercado capitalista mundial, com a promoção de avanço substancial dos direitos do grande capital financeiro em detrimento da soberania nacional. Com repactuação em bases desfavoráveis e duradouras da dívida externa, profunda abertura comercial, desnacionalização de setores produtivos e financeiroschave, desregulamentação do controle de fluxos de capitais e atrelamento dos gastos públicos a metas negociadas com o FMI, o país recém-democratizado perdeu para os mercados financeiros parte substantiva das deliberações sobre seu destino econômico.

Em segundo lugar, alterou-se o padrão dos direitos e deveres entre os cidadãos brasileiros. Se a Constituição 
de 1988 indicou um caminho de universalização de direitos sociais, o plano neoliberal de refundação do Estado brasileiro incorporou um ataque generalizado à lógica dos direitos dos trabalhadores. Rompeu-se a dinâmica de inclusão crescente no mercado formal de trabalho que vinha, em ritmos diferenciados, desde a Era Vargas. De potencial universalizante, as políticas sociais passaram a ter como meta o padrão focal, isto é, o objetivo de reduzir ao mínimo o projetado Estado do Bem-Estar Social no Brasil, deslocando o restante para o mercado e para políticas assistenciais dirigidas focalmente a grupos de extrema penúria (Vianna, 1998). Os impostos indiretos e a carga fiscal aumentaram muito para os assalariados, mas os ganhos do capital foram consistentemente protegidos da tributação. Uma nova onda de subsídios bilionários favoreceu grandes capitalistas, inclusive multinacionais ou setores que recentemente haviam se tornado donos de empresas estatais.

Em terceiro lugar, houve um deslocamento patrimonial do Estado - estimado em torno de 30\% do PIB - para grupos privados. Setores estratégicos da economia brasileira, fundamentais para qualquer plano de soberania econômica nacional, foram vendidos em condições pouco transparentes.

Em quarto lugar, alteraram-se as relações do pacto federativo e implementou-se uma relação que subordinou nitidamente o Congresso Nacional a uma dinâmica em que o Executivo detinha a iniciativa legislativa fundamental.

Uma refundação neoliberal do Estado brasileiro dessa magnitude, pela sua abrangência e profundidade, necessitaria ser apoiada em forte coalizão política. A síntese dessa coalizão política foi elaborada e ganhou realidade plena com a vitória de FHC em 1994.

Ela apoiou-se, em primeiro lugar, no forte deslocamento da cultura política: da agenda democrática dos anos 80 passou-se à agenda neoliberal dos anos 90 . A crítica histórica da chamada tradição populista, capitaneada pelo setor que se tornou hegemônico na USP e no Cebrap, fundiu-se nesse contexto com as tradições liberal conservadora e privatista dos partidos e grande empresariado brasileiro. Leu-se a crise brasileira como a crise final do Estado desenvolvimentista: o remédio estava nos mercados. Essa grande vitória político-cultural só pôde ser obtida no contexto da crise das tradições socialistas, socialdemocratas e desenvolvimentistas aprofundadas nos anos 80 no plano internacional.

O Plano Real, ao controlar a inflação, desenvolveu a base de popularidade para a grande coalizão das classes dominantes que já haviam massificado, através da mídia, a opinião de que o problema do Brasil tinha origem no excesso de Estado.

Em torno dessa vitória político-cultural, formou-se vasta coalizão, cobrindo o espectro do centro à direita, isolando as forças de esquerda, quebrando seu protagonismo, abrindo linhas de pressão sobre os movimentos populares, impondo, enfim, o controle coordenado sobre as condições necessárias para a refundação neoliberal do Estado brasileiro.

A conjuntura atual é marcada pela crise desse projeto. É o caráter estratégico dessa crise que abre novo período da conjuntura. Ele é marcado pela luta, em primeiro lugar, entre as iniciativas que visam renovar suas condições de continuidade e as que fazem oposição a esse projeto; e, ao mesmo tempo, pelas especulações sobre a alternativa que poderá sucedê-lo.

O caráter econômico da crise é evidente pelo fracasso do projeto em propiciar um novo período de crescimento sustentado do capitalismo brasileiro. Esse fracasso está exposto no crescimento médio da economia brasileira: $1,8 \%$ nos anos 90 , cerca de um terço da taxa verificada entre 1945 e 1980. Mais grave ainda, o plano neoliberal ampliou desequilíbrios de forma brutal - o endividamento público, o déficit externo, a desestruturação do setor produtivo estatal -, que impedem a retomada sustentada do crescimento. A recém-deflagrada, mas há muito anunciada, crise energética é a expressão clara da perda de um mínimo equilíbrio sistêmico da economia nacional.

O caráter social da crise, em parte decorrente do fracasso econômico estratégico, é impulsionado pela grave deterioração do mercado de trabalho no país. O desemprego aberto saltou de 4,5 milhões para mais de 7,64 milhões em 1999, segundo o IBGE. A informalidade, segundo a mesma fonte, elevou-se de $51 \%$ em 1989 para $59 \%$ em 1999. O gasto nas áreas sociais recuou de $18,5 \%$ do PIB em 1995 para 14,5\% em 2000. Nesse contexto, o Brasil assistiu à explosão da violência urbana na década de 90 .

No plano político, a crise do governo FHC é global. Incide sobre sua popularidade, que sofreu forte depressão no início de 1999 e cuja recuperação foi interrompida pelas crises sucessivas no primeiro semestre de 2001. Revelou-se de forma incisiva nas eleições municipais de 2000, com o avanço das forças de oposição, em particular do PT. Ganha agora novos contornos com a perda do controle sobre sua sucessão, tornando um segundo turno em 2002 muito provável e de resultados imprevisíveis. A disputa sucessória antecipada, por sua vez, levou a uma dinâmica de choques 
da antigamente coesa base governista, erodindo o controle do governo sobre o Congresso Nacional.

Por fim, a crise do projeto de refundação neoliberal do Estado brasileiro exibe sua face ética. A ideologia privatista, a desregulamentação dos controles financeiros, o caráter fisiológico da base governista e o insulamento burocrático das grandes agências econômicas do Estado, em contexto de massivos deslocamentos patrimoniais, geraram condições propícias à corrupção.

É nesse contexto que se delineia a construção de candidaturas para as eleições de 2002. Elas tendem a concentrar e absorver toda a dinâmica política da atual conjuntura. Este ensaio pretende, a partir desses parâmetros gerais, investigar as tendências mais visíveis da dinâmica política do país no próximo período.

\section{ECONOMIA E POLÍTICA}

O primeiro grande desafio é pensar qual o impacto da evolução da conjuntura econômica brasileira na cena política. Menos do que acrescentar mais uma aposta na banca de previsões, trata-se de sugerir parâmetros de interpretação.

O primeiro parâmetro poderia ser assim enunciado: $a$ influência da economia sobre os rumos da política é mediada pelo modo como os atores lêem a realidade econômica e dela se apropriam, a partir de suas visões de mundo, valores e interesses.

Ora, se a concepção liberal de mundo predominou no Brasil nos anos 90, foi exatamente em sua versão mais nitidamente economicista e neoliberal que ela se fez presente. A impregnação da cultura política do país e do senso comum por esse economicismo explica o aparente paradoxo de $\mathrm{FHC}$ ter-se beneficiado politicamente na primeira eleição da explosão de consumo inicialmente produzida pelo Plano Real e, na reeleição, da problemática iminência de uma crise cambial.

Um segundo parâmetro interpretativo: na complexa interação entre economia e política, são os vetores desta última que indicam os caminhos de evolução da conjuntura. Isso quer dizer que a luta política é centralmente condicionada (mas não determinada) pela evolução da economia, e decide-se pelas opções e práticas dos atores coletivos presentes na cena. A política não é um reflexo da economia nem há mera configuração mútua e indeterminada de instâncias autônomas da realidade social.

Isso é decisivo para a avaliação da conjuntura brasileira atual. A imprevisibilidade das eleições de 2002 significa imprevisibilidade do aparato de regras, prioridades e arranjos que condicionam centralmente as taxas de lucro e os ganhos esperados pelos agentes mercantis no Brasil. O grau dessa imprevisibilidade expõe, na linguagem dos mercados, o grau de risco Brasil, repercutindo fortemente nos fundamentos macroeconômicos já em estado de desequilíbrio da economia. Essa é uma das razões da nervosa elevação do dólar em relação ao real, diante das evidências de instabilidade da coalizão governamental e de seus planos. É função dessa imprevisibilidade tornar prioritário na agenda do governo o que vem sendo chamado de blindagem institucional, isto é, a votação que prevê uma autonomia relativa do Banco Central e de suas políticas em relação ao futuro presidente eleito.

Um terceiro parâmetro incorpora a análise estrutural da evolução brasileira na última década: ao optar por uma lógica mercantil inteiramente subordinada às flutuações internacionais, ao invés e em desfavor de uma lógica sistêmica nacional, a coalizão governante modificou estruturalmente as relações entre as variáveis sob seu controle e a força do imprevisivel na evolução da conjuntura brasileira.

O êxito do projeto estratégico de FHC fundou-se desde o início na expectativa de que as conjunturas internacionais seriam favoráveis. Desde 1997, pelo menos, não o são e os circuitos financeiros internacionais acomodamse nervosamente de crise em crise (Sallum Jr., 2000). Das variáveis levadas em conta pelos analistas econômicos para fazer previsões (taxa de crescimento da economia norteamericana e taxa dos juros fixados pelo FED; evolução dos preços do petróleo; risco Argentina e de outros mercados emergentes em crise; evolução dos fluxos dos investimentos externos), quais são hoje de fato controladas pelo governo FHC?

Um último parâmetro, enfim, advém igualmente da análise estrutural do projeto FHC: este não gerou um patamar de crescimento econômico contínuo e sustentado, que alterasse qualitativamente o contexto de impasse dos anos 80, criando incorporação social e espaço histórico numa dinâmica hegemônica do projeto hoje dominante.

Devemos a Francisco de Oliveira (1998) a reflexão inteligente sobre o que havia de domínio ideológico orquestrado no predomínio do neoliberalismo no Brasil dos anos 90 e a ausência de uma dinâmica hegemônica socialmente consistente. O domínio institucional do governo - hiperconcentração de poderes no Executivo, controle relativamente estável de maioria parlamentar, cumplicidade governativa na alta cúpula do Judiciário - não se compôs com legitimidade social ao longo do tempo. 
O crescimento da economia em 2000 operou apenas alteração na margem do desemprego acumulado e conviveu com perda do rendimento médio dos assalariados. É evidente que a continuidade do crescimento, mesmo contido e instável, cria potencialmente melhor posicionamento das forças continuístas na disputa sucessória. Mas o que se anuncia para 2001, após as evidências da crise energética, é um crescimento bem aquém dos $4,5 \%$ antes esperados, na hipótese mais otimista trabalhada pelo governo. Para 2002, o quadro é ainda mais incerto.

\section{BRASIL E ARGENTINA}

As semelhanças e diferenças com a vizinha crise argentina ajudam a compreender a evolução da crise brasileira.

Em "Argentina em transe" o cientista político Guilhermo O’Donnell (2001) traça de longe o mais acurado diagnóstico do impasse dramático e estrutural do país vizinho. $\mathrm{O}$ domínio do capital financeiro, segundo O'Donnell, ameaça corroer as bases mínimas do funcionamento da democracia argentina. Anti-social e antinacional, o capital financeiro internacional impôs uma política macroeconômica cujo "interesse racional é equilibrar, por um lado, a capacidade de o país continuar pagando e, por outro, maximizar os juros que cobra". Criou-se, assim, "um grau de dependência como não sonharam os textos mais pessimistas sobre dependência escritos há algumas décadas". A própria política perde substância e as alianças não mais projetam estratégias políticas, mas "contratos de compra e venda de pouca duração e baixa densidade".

Um raciocínio impressionista poderia levar a examinar o contexto brasileiro a partir da dinâmica límpida vivida pela Argentina. Mas há, apesar das linhas fortes de semelhança, diferenças estruturais decisivas: o grau de desestruturação produtiva, de crise fiscal e desorganização do setor público e de exposição à especulação financeira é significativamente maior lá do que aqui. Em contraste, no Brasil, a crise social é hiperdimensionada em relação à Argentina em função do maior grau de concentração da renda.

Mais importante ainda do que tudo isso, no entanto, é a desmoralização política que na Argentina se expressou na viragem neoliberal do que restava da tradição peronista e a ausência de uma força de esquerda, com raiz social e densidade eleitoral. No Brasil, as forças políticas e intelectuais que podem alimentar um novo republicanismo, democrático e social, são muito mais expressivas.

Feitas essas ressalvas decisivas, que nos protegem do vício da analogia, a contribuição de O’Donnell pode aju- dar a iluminar as raízes sociais profundas da atual crise política brasileira. No Brasil de FHC, a dinâmica financeira descrita por O'Donnell, a racionalidade de gerar capacidade estatal de pagar dívidas para pagar juros cada vez mais altos também orienta a política macroeconômica do país. Durante todos esses anos, o Brasil esteve na linha de frente dos governos que sustentaram os juros mais altos do mundo.

De 1995 a 1999, o Tesouro Nacional pagou, segundo Ribamar Oliveira (Valor, 16/04/2001), 109 bilhões de reais em juros de suas dívidas externa e interna. Acumulou, somente nesse período, juros devidos no montante de 222,9 bilhões de reais. A contrapartida é a necessidade crescente de vender ativos e gerar superávits primários (receitas menos despesas correntes, excetuando juros). O mesmo articulista analisa as metas fiscais previstas no projeto da Lei de Diretrizes Orçamentárias, encaminhado pelo governo ao Congresso no início de abril: um superávit primário de 3\% do PIB de 2002 a 2004. Em linguagem mais clara, seriam seis anos acumulados de excessivo arrocho nos gastos do Estado, em particular nas políticas sociais. A medida é justificada oficialmente como modo de dar aos credores internacionais confiança no pagamento de sua dívida, custe o que custar.

\section{A CENA POLÍTICA}

O grande efeito das eleições municipais de 2000 foi descongelar o passado e reabrir as promessas do futuro. É só a partir da referência ao ciclo político aberto em 1994 e às incertezas da sucessão presidencial de 2002 que os erráticos e nervosos movimentos da conjuntura atual podem ser coerentemente interpretados.

O principal fundamento da atual coalizão governante, mais ampla e programaticamente definida que aquela formada em torno de Tancredo Neves, era a certeza da própria continuidade. Inaugurou-se com o selo propagandístico, tornado quase senso comum, que iniciava uma era de vinte anos no poder. A reeleição tornou-se o epicentro das prioridades e ritmos das políticas do governo federal no primeiro mandato de FHC. As eleições presidenciais de 1998 realizaram-se, em meio à iminência de uma grave crise cambial, em um quadro de evidente chantagem frente ao eleitorado: ou continuidade ou o caos. O próprio presidente do Superior Tribunal Eleitoral afirmou à época que a definição das eleições no primeiro turno seria propícia e necessária ao país.

Agora, não. Um segundo turno é muito provável e é grande a margem de imprevisibilidade dos resultados. A 
pesada âncora política, que mantinha incólume a nau governamental, veio à tona. O controle de maioria no Congresso mostra suas brechas. O consenso programático nas bases do poder, antes pretensiosamente auto-referido, ameaça tornar-se público dissenso. Lideranças políticas e intelectuais ligadas ao PSDB têm vindo reiteradamente a público colocar em questão temas que eram quase um dogma programático - as privatizações do setor hidroelétrico, a ausência de uma política industrial ativa, a estratégia de abertura comercial e de integração à Alca, etc.

Mas 2002 não está para 2000 assim como 1989 esteve para 1988. Neste ano, também as esquerdas protagonizaram espetaculares sucessos eleitorais municipais, indicando potencial inédito de crescimento nas eleições presidenciais de 1989.

Agora, é o dobro o tempo para processar os resultados eleitorais municipais. O governo FHC goza de uma capacidade de iniciativas bastante superior à do governo Sarney, que viveu seu último período absolutamente refém de forças centrífugas. Tem, portanto, mais capacidade para ser ator na própria sucessão. Inserida no tempo da sucessão presidencial, a conjuntura política de 2001 movese nervosamente entre passado e futuro.

O cientista político Wanderley Guilherme dos Santos (2000), em entrevista ao Jornal do Brasil, lembrou que, com todo o avanço da esquerda, os partidos da base governista conquistaram ainda $60 \%$ dos votos. David Fleischer (2001), da UNB, comentou em artigo que na cúpula do PSDB os resultados foram assim decompostos: “1) nas 5.200 cidades com menos de 62 mil habitantes, o PMDB recebeu mais de $50 \%$ dos votos; 2 ) na faixa intermediária de 193 cidades entre 60 mil e 300 mil habitantes, o PSDB levou a melhor com $27 \%$ dos votos; 3 ) nas 166 cidades com mais de 300 mil habitantes, o PT ficou em primeiro lugar, também com $27 \%$ dos votos".

Em eleições casadas, as ramificações municipais contam muito. Conta mais, porém, o dinamismo instalado em eleições presidenciais: as incertezas de 2002 quebram qualquer projeção linear de futuro. $\mathrm{E}$ as pesquisas de hoje têm certamente um valor bastante provisório.

A soma dos votos dos partidos pró-FHC em 2000 (PSDB, PFL, PMDB, PPB e PTB) foi de 52.364.673, bem mais alta que os 35.936 .918 votos recebidos por FHC reeleito em 1998. Uma parte minoritária, mas não inexpressiva, do PMDB fez campanha oposicionista a FHC nas eleições de 2000. Os votos do PPS em 2000 foram seis vezes mais numerosos que em 1996, mas menos da metade dos 7.426.235 votos obtidos por Ciro Gomes em
1998. O voto no PT em 2000 cresceu 51, 2\% em relação às eleições municipais de 1996 mas, mesmo assim, foi apenas um pouco mais da metade dos 21.475.346 votos de Lula em 1998. Itamar, hoje refiliado ao PMDB, se tornada viável sua candidatura à presidência, deslocará uma massa de votos certamente não desprezível.

Há, assim, uma espécie de pirâmide invertida no que se refere à relação entre as candidaturas mais visíveis e respectivas bases partidárias. Os três nomes da oposição que aparecem mais votados nas pesquisas estimuladas Lula, Ciro, Itamar - projetam massas de votos para além das respectivas bases partidárias. Os candidatos potenciais da base do governo, refletindo a concentração egótica na imagem de FHC, estão ainda bem aquém do seu potencial de voto. Essa ausência de correspondência, em um eleitorado de 108 milhões de indivíduos, dos quais apenas cerca de $40 \%$ revelam alguma preferência partidária, é, por assim dizer, uma fotografia da instabilidade que caracteriza o momento. $\mathrm{O}$ fato de os principais nomes que ocupam o cenário das eleições de 2002 - FHC e seu sucessor, Itamar (ex-presidente no Plano Real), Ciro Gomes (ex-ministro da Fazenda no Plano Real) e Lula (ou um candidato por ele apoiado) - terem sido também personagens centrais em 1994 evidencia que a disputa do futuro implicará certamente um acerto de contas com o passado recente.

A incerteza do futuro coloca para a direção da coalizão governista, em particular para o PSDB, um problema de identidade, de estratégia e de cálculo. Identidade: as eleições de 1998 mostraram que nem sempre são convergentes e podem ocorrer tensões importantes entre os interesses do PSDB e do governo FHC. Este, para garantir a vitória no primeiro turno, vista como necessária para enfrentar a crise cambial, optou por diminuir as chances de vitória nas eleições para os governos de São Paulo, Minas e Rio, aliando-se também com candidaturas regionalmente adversárias do PSDB. A construção interrompida de alternativa para a sucessão presidencial por Covas, a candidatura Aécio Neves à presidência da Câmara, a dissidência pública de Mendonça de Barros às políticas do governo (agora, em formato editorial na revista Repúbli$c a$ ), a tendência a nova ênfase de alianças no interior da coalizão governamental em favor do PMDB e em detrimento do PFL revelam a busca de nova identidade pública para o partido. Ora, a maior autonomia do PSDB relação ao centro do poder implica necessariamente disputas de focos de poder regional já que a tradição do PSDB é fortemente federativa. 
Estratégia: entre um continuísmo retemperado e uma continuidade que recomeça, absorvendo e neutralizando bandeiras da oposição, a distância, aparentemente sutil, pode ser decisiva e implica estratégias diversas de nomes, marketing e alianças.

Cálculo: as eleições de 1998 para FHC já dependeram centralmente da estratégia de coalizões (Roma, 1999). As de 2002 dependerão mais ainda, no contexto de popularidade em baixa. Qual seria a parceria principal: PFL ou $\mathrm{PMDB}$ ? Ou, ainda, quais setores privilegiar nesses partidos fisiologicamente fragmentados? Entre as dúvidas de identidade, estratégia e cálculo, há ainda o personagem a ser ungido pela coalizão governativa, a fogueira das vaidades e dos círculos de poder.

\section{A CRISE PARLAMENTAR}

Desde o primeiro semestre de 1999, havia uma assimetria entre a perda de popularidade de FHC e seu controle incontestável de maioria no Congresso.

Os primeiros meses de 2001 registraram intenso abalo sísmico no território até então inexpugnável da coalizão governista. As disputas pelas presidências na Câmara Federal e no Senado, projetando diferentes alianças para 2002, a dissidência ACM, o escândalo agora tornado explosivo da violação da votação (ou votações) no Senado, envolvendo o líder do governo filiado ao PSDB, as denúncias de corrupção praticadas pelo presidente recém-eleito do Senado, o apoio a uma CPI mista investigando o próprio núcleo do governo são indícios mais que suficientes da crise. O Congresso Nacional, de trincheira da governabilidade, passou a epicentro de uma instabilidade cujos limites são imprevisíveis.

São três as razões dessa mudança fundamental. Em primeiro lugar, a aproximação do fim de um governo que não tem mais a capacidade segura de eleger seu sucessor.

Além disso, a crise de popularidade de $\mathrm{FHC}$ torna mais sensível a base governista ou, pelo menos, alguns setores dela à pressão da opinião pública em véspera de renovação de mandatos. O custo de apoiar o governo incondicionalmente ficou mais alto.

Em terceiro lugar, com a sinalização dada pela direção do PSDB de uma aliança preferencial em 2002 com o PMDB, em detrimento do PFL, foi posta em questão a própria estabilidade da coalizão parlamentar do governo.

O livro Executivo e Legislativo na nova ordem constitucional, de Argelina Figueiredo e Fernando Limongi (1999), ajuda-nos a compreender a ordem parlamentar vigente nos anos 90, agora em crise.
Segundo os autores, a Constituição de 1988 propiciou um novo tipo de relação Executivo/Parlamento em relação ao período 1946-1964. As atenções dos analistas, em geral, têm-se concentrado no instituto das medidas provisórias, que revela certa continuidade dos decretos-lei da época do regime militar, embora tornado relativo por certos procedimentos antes inexistentes. Prevalece no meio jurídico a convicção de que o governo tem abusado inconstitucionalmente do poder desse instituto.

A tese dos autores, no entanto, vai muito além do exame das medidas provisórias. $\mathrm{O}$ que se teria firmado na década de 90 seria um presidencialismo de coalizão, com eixo nos partidos, impondo um padrão de fato aproximado de certas dinâmicas típicas de sistemas de governo parlamentaristas. O presidencialismo de coalizão implicaria uma dinâmica bastante diversa do padrão presidencialista norte-americano, que prevê grande importância para o trabalho das comissões parlamentares e para a atuação individual de senadores e deputados.

No Brasil dos anos 90 - em particular no período mais estável do governo $\mathrm{FHC}$-, o presidente compõe seus ministérios fazendo negociações com partidos. Obtém, através dessas participações, a lealdade de suas cúpulas. $\mathrm{O}$ funcionamento da Câmara e do Senado apoia-se em dinâmica centrada nos líderes partidários de bancada. Nesse tipo de funcionamento, o espaço para a atuação pessoal do parlamentar e o custo da dissidência em relação ao governo são mais altos. Diminui também o espaço para a atuação das oposições. Por essa dinâmica, o governo, que em geral detém a iniciativa legislativa, consegue altíssimos índices de aprovação para seus projetos de lei.

Os dados, pesquisados pelos autores, são realmente muito expressivos. Entre 1989 e 1998, o Executivo transformou em lei 1.606 dos 2.074 dos projetos enviados. Apenas 24 foram rejeitados e 10 vetados totalmente. $\mathrm{O}$ restante ou foi retirado ou está em tramitação. De iniciativa dos parlamentares, foram apresentados 16.217 projetos de lei; apenas 262 foram aprovados. A agenda do Executivo é predominantemente econômica e administrativa, enquanto a do Legislativo é social.

Os votos de bancada, quando há votação nominal, seguem em geral os votos das lideranças. A disciplina média plenário foi de $89,9 \%$. Em mais de nove entre dez votações, a coalizão presidencial contou com o apoio de todos os líderes partidários que receberam pastas ministeriais. Em média, $86,7 \%$ dos deputados filiados aos partidos que dão sustentação ao governo votam em apoio à agenda do presidente. 
Ora, a aliança PSDB-PFL estruturava o cerne da base parlamentar governista. O PFL era o mais disciplinado dos partidos de direita. O PMDB, menos disciplinado, embora siga a tendência geral. O conflito com ACM pôs, assim, em turbulência o núcleo duro da base governamental em todos esses anos.

\section{SIGNIFICADO DA CRISE ÉTICA}

Após a experiência traumática do governo Collor, na qual crime e improbidade administrativa eram como que irmãos siameses, a intelectualidade e a opinião pública brasileira viam no governo FHC uma possível saída para a situação crônica da corrupção. Várias setas pareciam indicar essa direção: o passado tido como honrado e honesto de um intelectual respeitável, a imagem do PSDB nascido na crítica às práticas fisiológicas do PMDB, a crítica do estatismo que, na leitura liberal da tradição política brasileira, figura como a origem dos males da corrupção no Brasil. Havia, é certo, uma sombra: a aliança com o PFL. Mas, este não foi ungido, no entusiasmo intelectual da hora da vitória, à condição de moderno?

A história recente dos dois mandatos de FHC desmentiu a previsão. Há, no mínimo, quatro razões que explicam a explosão da corrupção no Brasil contemporâneo.

A primeira delas é exatamente o enfraquecimento das fronteiras entre o público e o privado, ou melhor, a mais completa subordinação do primeiro ao segundo, como resultado do núcleo da opção programática da coalizão liderada por FHC. Isso quer dizer que seu sentido nuclearmente anti-republicano, a exaltação do privado e o aviltamento do que é público, convenientemente confundido com o que é estatal, ampliou o espaço para a corrupção.

Em segundo lugar, o plano de governo de FHC pressupunha a solda de uma base parlamentar amplíssima, necessária à aprovação das reformas da Constituição. Ora, esta base e loteamento de ministérios combinam-se na tradição presidencialista brasileira. O fisiologismo, assim, foi desde o início incorporado ao núcleo da estratégia de governo.

Em terceiro lugar, a autarquização dos centros decisórios e o chamado insulamento burocrático compõem centralmente a dinâmica típica de governos de agendas neoliberais (Diniz, 1997). São estritamente necessários para o enlace das grandes agências estatais - BNDES, Banco Central, Banco do Brasil, Fundos de Pensão, etc. - com grandes grupos econômicos.

A consciência do brasileiro já captou a importância decisiva da ética na política para seus interesses desde os tempos da transição. Já no início da década de 90, José Álvaro Moisés evidenciava, através de pesquisas, o aparente paradoxo de que a crescente adesão dos brasileiros aos valores da democracia ia de par com a persistente insatisfação com o funcionamento do sistema político e com a desconfiança em relação aos "políticos" (Moisés, 1993). A pesquisa de opinião pública "Cultura política e cidadania”, feita pela NOP - Fundação Perseu Abramo, em dezembro de 1997 , apontava que $43 \%$ dos brasileiros escolhiam seu candidato a partir do "seu caráter moral"; apenas $14 \%$ votavam a partir "das proposições de governo do candidato". Não se trata, de forma alguma, de uma despolitização do eleitor: de que valem programas se não está estabelecida a veracidade da mensagem?

O fenômeno da ética na política não recebeu ainda tratamento adequado por parte da alta cultura política brasileira, em particular por parte daquelas forças mais interessadas na transformação e aprofundamento da democracia. A opinião pública ainda não encontrou uma resposta ético-política suficientemente expressiva para suas intuições de que a democracia não prospera onde a ética degenera.

Há na cultura política, grosso modo, três modos de se estabelecer a relação entre a democracia e a ética. A primeira, com origem na obra de Max Weber, é de que a modernidade é marcada pela cisão da ética, pela pluralidade de valores, não sendo mais possível fundamentar democraticamente uma ética de cunho universal. A democracia, então, é definida pelos procedimentos ou por uma técnica jurídico-política de formar governos legitimados. A relação entre a ética e a política não seria da ordem do público, mas tratada no plano da subjetividade do político, que deve equilibrar a ética das convicções (agir segundo seus valores) e a ética das responsabilidades (agir segundo as conseqüências previstas de seus atos). Essa tese tem hoje incidência muito forte na alta cultura, em um liberalismo conservador e elitista. Através dela, o diagnóstico do problema político brasileiro passaria pela pouca sedimentação dos procedimentos legais da democracia, cabendo então apenas processualmente afinar seu uso, eficácia e respeito a eles.

Um segundo modo de conceber o problema da ética na política seria o de um liberalismo ético que busca a verdade na representação política. Coube a Olavo Brasil de Lima Junior (1993), em seu brilhante livro Democracia e instituições politicas no Brasil dos anos 80, demonstrar como as preferências eleitorais dos brasileiros, manifestadas nas primeiras eleições realizadas após a transição do regime militar, eram distorcidas pela representação 
partidário-parlamentar com a criação de novas siglas e mudanças em massa de partido por parte de políticos eleitos. Segundo ele, "a desvinculação entre os sistemas partidário-parlamentar e eleitoral é síndrome, e simultaneamente parte, do distanciamento mais geral entre sociedade e política no país". Carlos Ranulfo, professor de Ciência Política da UFMG, evidenciou que o fenômeno da mudança de partido por parte de parlamentares no Congresso Nacional ganhou proporções avassaladoras nos anos 90 (Melo, 2000). A partir desse diagnóstico, o problema básico da relação entre ética e política - o da fraude na representação - só pode ser resolvido por uma reforma política da legislação eleitoral e partidária, que estabeleça novos critérios de fidelidade partidária, que aproxime a representação de um critério conforme à proporcionalidade estrita entre número de eleitores e quota de eleitos, que introduza o financiamento público dos partidos e regule o financiamento privado das campanhas, entre outras medidas.

Há, porém, uma terceira ótica para se analisar a crise ética do sistema político brasileiro: a ótica republicana, que diagnostica o problema no prevalecimento dos interesses privados sobre os públicos, pensados a partir de uma lógica democrática da soberania popular. Por essa visão, existem de fato problemas-chave de procedimento democrático e de funcionamento do sistema de representação. Mais do que isso, porém, a raiz da crise ética do sistema político brasileiro seria a distância substantiva entre sua pretensão de ser universal e sua reiteração como sistema cuja lógica funciona para manter privilégios. A democracia brasileira não foi capaz ainda, como demonstrou o recente censo do IBGE, de alterar os padrões de concentração de renda erigidos no período do regime militar.

\section{A DINÂMICA DA CRISE}

Imediatamente após reeleição e diante da grave crise cambial que levou o governo aos braços do FMI, Fernando Henrique Cardoso proclamou que seu segundo governo não seria refém da administração da crise. O programa de refundação liberal do Estado brasileiro continuaria, consolidando o domínio da coalizão formada em 1994 e ampliada em 1998.

No primeiro semestre de 2001, porém, houve uma precipitação de acontecimentos que se somaram na direção de retirar poder político do governo. A penosa gestão dos fundamentos da própria governabilidade passou a consumir mais e mais suas energias. A capacidade de iniciati- vas do governo decaiu na mesma medida em que cresceram a força e a audiência das oposições.

Agora, o que desperta atenção é o que poderíamos chamar de efeito antecipação: a disseminação da expectativa de que o governo FHC chegue às eleições de $2002 \mathrm{em}$ meio à crise e altíssimos índices de impopularidade faz com que os atores migrem para alternativas de oposição, gerando um efeito circular de alimentação da crise do governo. Esse já é o caso do PTB, de parte do PFL e talvez do PMDB. A situação deste último é decisiva: se em sua próxima convenção nacional vencerem as forças que querem afastá-lo do governo e de seus planos de sucessão, então será muito difícil para um PSDB em crise definir o campo da própria sucessão.

Os efeitos políticos da maior crise energética da história do país apenas começaram a ser sentidos. Segundo vários especialistas, na melhor das hipóteses, o racionamento durará até o final de 2002, não sendo, aliás, descartados os apagões, mesmo com o aumento punitivo das tarifas. A situação do Nordeste é particularmente aflitiva. Para o BNDES, mesmo com o investimento de 45 bilhões de reais, a escassez de energia deve durar até 2003. A própria capacidade do governo de gerir uma crise tão complexa é posta seriamente em questão pela maioria da população ouvida.

São três os efeitos imediatos da crise energética. Em primeiro lugar, promove forte aumento da impopularidade de FHC. Em segundo lugar, enraiza-se solidamente na opinião do brasileiro o posicionamento contra o paradigma neoliberal, em particular as privatizações. Antes da crise energética, pesquisas já apontavam para o desgaste do paradigma neoliberal. A crise deve consolidar esse sentimento.

Em terceiro lugar, torna-se dramática a já dificílima situação macroeconômica do Brasil. A crise energética corta as expectativas de crescimento para o país (estimado agora por várias instituições em pouco mais de $2 \%$ contra $4,4 \%$ no início do ano) e torna muito mais vulnerável o balanço de pagamentos (maior déficit comercial, menos investimentos externos). Até o fím do mês de maio, o dólar acumulou uma alta de $20 \%$ no ano de 2001 , com efeitos acumulados sobre a dívida pública.

\section{ENTRE O PASSADO E O FUTURO}

Sob o título "Eleitor pobre quer nacionalista no poder. Sondagens colocam em desvantagem os candidatos que representam a continuidade", o jornal Valor Econômico 
(02/04/2001) traz informações interessantíssimas captadas por agências de opinião.

A pesquisa aponta que $10 \%$ dos ouvidos eram totalmente favoráveis à privatização mas $37 \%$ eram totalmente contrários. Maior a renda, maior a simpatia pela privatização. Um número considerável opinou que empresas estatais não deveriam ter o direito de comprar estatais brasileiras. A resposta a perguntas sobre as funções que o Estado deveria exercer, afirma o artigo assinado por Maria Inês Nassif, ainda aponta para um sentimento profundamente estatista.

A opinião pública, sabemos, forma-se elaborando as informações recebidas e as experiências vividas empiricamente a partir de modelos argumentativos lógicos e de valores. O que a pesquisa revela é a alteração que está em curso na opinião do brasileiro. Um modelo interpretativo está em crise e outro ainda não foi construído.

Uma mudança de cultura política como essa nunca é univocamente determinada. Não é simples reflexo da vida material, embora esteja fortemente relacionada a ela. "O discurso neoliberal foi eficiente enquanto teve forte elemento economicista", analisa o cientista político Antônio Prado, no artigo citado. A outra parte, essencial, é que a mudança em curso do senso comum revela uma vitória decisiva das batalhas político-culturais dos que resistiram ao paradigma neoliberal de refundação do Estado brasileiro, seja no plano da alta cultura, nacional e internacional, na mídia, seja no plano da luta político-partidária ou da mobilização popular. Socialistas, liberais éticos, comunitaristas cristãos e desenvolvimentistas, as lideranças que organizam a consciência democrática do povo brasileiro, tão duramente construída nas últimas décadas, participaram da grande frente de resistência a um pensamento que se queria único.

Afirma-se com freqüência e com razão que a tradição política brasileira resiste a mudanças profundas, atualiza permanentemente o passado e impregna o futuro do movimento circular da mesmice. Mas seria fechar os olhos à realidade não registrar o peso crescente das forças da mudança que podem, em uma conjuntura crítica, repor os padrões republicanos. Tudo indica que nas eleições de 2002, realizadas sob a crise do paradigma neoliberal, as forças democráticas terão a oportunidade rara de equacionar um melhor futuro novo para o País.

\section{REFERÊNCIAS BIBLIOGRÁFICAS}

COUTO, C.G. "A longa Constituinte: reforma do Estado e fluidez institucional no Brasil”. Dados. Rio de Janeiro, Iuperj, n.41, 1998, p.51-86.

DINIZ, E. Crise, reforma do Estado e governabilidade. Brasil, 1985 95. Rio de Janeiro, Editora da Fundação Getúlio Vargas, 1997.

FIGUEIREDO, A. e LIMONGI, F. Executivo e legislativo na nova ordem constitucional. Rio de Janeiro, Fundação Getúlio Vargas, 1999.

FLEISCHER, D. "Lições das urnas: as eleições municipais de 2000 e as conseqüências para 2002". Boletim de Análise de Conjuntura. Minas Gerais, DCP-UFMG, jun. 2001.

GUIMARÃES, J. Democracia e marxismo: crítica à razão liberal. São Paulo, Xamã, 1999.

LIMA JÚNIOR, O.B de. Democracia e instituições politicas no Brasil dos anos 80. São Paulo, Loyola, 1993.

MELO, C.R.F. de. "Por que mudam de partido os deputados brasileiros?". Teoria \& Sociedade. Revista dos Departamentos de Ciência Política e de Sociologia e Antropologia. Belo Horizonte, out. 2000, n.6, p.122-77.

MOISÉS, J.Á. "Democratização e cultura de massas no Brasil." Lua Nova. São Paulo, Cedec, n.26, 1993.

O’DONNELL, G. “Argentina em transe”. Folha de S.Paulo, 15/04/2001, Cad. Mais.

OLIVEIRA, F. Os direitos do antivalor. A economia politica da hegemonia imperfeita. Petrópolis, Vozes, 1998.

ROMA, C.R. "Política de alianças e desempenho eleitoral: um estudo sobre as estratégias de competição do PSDB, 1988-1998.” XXI Congresso Nacional da Anpocs, GT 08 Mídia, opinião pública e eleições, 1999.

SALLUM JR., B. “O Brasil sob Cardoso: neoliberalismo e desenvolvimentismo." Tempo Social. Revista de Sociologia da USP. São Paulo, fev. 2000, v.11, n.2, p.23-47.

SANTOS, W.G. dos. "A base governista ganhou.” Entrevista ao Jornal do Brasil, 15/10/2000.

VIANNA, M.L.W. A americanização (perversa) da seguridade social no Brasil, estratégias de bem-estar e politicas públicas. Rio de Janeiro, Revan, UCAM, 1998. 